\title{
Google Sala de Aula como Ambiente Virtual de Aprendizagem no Ensino Superior Híbrido: Uma Revisão da Literatura
}

\author{
Sumária Sousa e Silva*1 \\ Antônio Carlos Pereira dos \\ Santos Júnior ${ }^{2}$ \\ 12 Universidade do Estado de \\ Mato Grosso (UNEMAT), Campus \\ Universitário Deputado Estadual \\ Renê Barbour. Rua A s/n, Bairro São \\ Raimundo, Barra do Bugres- MT, Brasil. \\ * sumariasousa@gmail.com
}

\section{Resumo}

A presente pesquisa teve como objetivo mostrar as potencialidades do Google Sala de Aula como ambiente virtual de aprendizagem no ensino superior híbrido. Para tanto realizamos uma pesquisa bibliográfica do tipo integrativa com uma abordagem quanti-qualitativa. O recorte temporal foi de 2014 a 2018 e as buscas ocorreram em banco de dados como o Google Acadêmico e o Portal de Periódicos da Capes. Os resultados apontaram um crescente aumento de publicações sobre a temática, principalmente a partir de 2017, que incluíram tanto trabalhos teóricos quanto experimentais, do tipo relato de experiência e estudo de caso. Observou-se ainda que esta ferramenta está sendo usada em diferentes áreas, como: Direito, Matemática, História e Química, principalmente o modelo de ensino híbrido sala de aula invertida. Concluiu-se que existe um consenso entre os pesquisadores sobre características, competências e habilidades necessárias para o uso de plataformas digitais no ensino híbrido. Além disso observamos a relevância desses estudos em relação à construção de estratégias didáticas e pedagógicas para orientação do processo de ensino e aprendizagem e a organização de ambientes virtuais de aprendizagem adaptáveis.

Palavras-chave: Cultura digital. Ensino híbrido. Virtualização do ensino superior. 


\section{Google Classroom as Virtual Learning Environment in Higher Education Hybrid Programs: A Literature Review}

\section{Abstract}

The current research aimed to show the potential of Google Classroom as a virtual learning environment in higher education hybrid programs. An integrative research review was carried out with quantitative-qualitative approach. The considered time was from 2014 to 2018 and searches were done on databases such as Google Scholar and the Capes Portal of Journals. The results pointed out a growing number of publications on the subject, mainly from 2017, including both theoretical and experimental works, such as experience reports and case studies. It was observed that this tool is being used in different areas such as Law, Mathematics, History and Chemistry, mainly the hybrid learning model flipped classroom. It was concluded that there is a consensus among researchers about the characteristics, skills and abilities required for the use of digital platforms in hybrid education. In addition, there is relevance of these studies in relation to the construction of didactic and pedagogical strategies to orient the teaching and learning process and the organization of adaptive virtual learning environments.

Keywords: Digital culture. Hybrid education. Virtualization of higher education.

\section{Introdução}

Pesquisadores, educadores, gestores, e alunos vivenciam um aumento no uso de ambientes virtuais de aprendizagem desde a segunda metade da década de 1990 (MACIEL, 2013). De acordo com Moran (2015) existe uma busca constante de transformar o universo educacional em ambientes motivadores aos estudantes, onde o aluno passa a ser o protagonista do seu aprendizado. Valente, Almeida \& Geraldini (2017) destacam como um dos desafios da educação o repensar sobre novas propostas educativas que superem a instrução ditada pelo livro didático, centrada no dizer do professor e na passividade do aluno. E que é importante considerar a cultura digital, marcada pela criação e abertura de limites espaciais e temporais da sala de aula. A exploração dessas características demanda reconsiderar o currículo e as metodologias que colocam o aluno no centro do processo educativo e focam na aprendizagem ativa.

No entanto, ainda existe um distanciamento entre a realidade do estudante em sala de aula e as propostas educacionais tecnológicas. Mendes e Leme (2014) afirmam que essa lacuna não restringe apenas aos recursos de hardwares ou softwares, mas de verificar se os recursos tecnológicos são capazes de solucionar as dificuldades encontradas por estudantes e professores. Entende-se, portanto, que, não somente é necessária a tecnologia, mas como utilizá-la dentro da sala de aula. De forma a difundir mudanças na abordagem pedagógica para construção do conhecimento, dinamizada pela colaboração (FARIA, 2004).

Nos últimos anos observa-se o crescimento de cursos de ensino a distância ${ }^{1}$, que utilizam as TDICs e por outro lado, cursos cuja a modalidade é o ensino presencial que também passaram a beneficiar-se dessas experiências. A adoção dessas novas práticas provoca de certa forma, uma confusão, quando se busca

1 Cabe ressaltar aqui a diferença entre Ensino a Distância e Educação a Distância; o ensino representa instrução, socialização de informação, aprendizagem, etc., enquanto a educação é estratégia básica de formação humana (Rezende \& Dias, 2010). E, portanto, neste trabalho será adotado a expressão ensino a distância. 
discernir estratégias específicas de ensino e aprendizagem para cursos de ensino a distância daquelas de cursos de ensino presencial (SANCHO \& HERNÁNDEZ, 2006).

Diante desse novo cenário educacional a integração entre o ensino presencial e o virtual vem sendo foco de diversos estudos no cenário mundial. Tori (2010) descreve o surgimento de um fenômeno de convergência entre o virtual e o presencial, também conhecido como Blended Learning (b-learning), em português Ensino Híbrido. Esse modelo de ensino estimula não apenas a aplicação de recursos para o gerenciamento de conteúdo e processos de ensino-aprendizagem em ensino a distância, mas também o uso de TDICs na perspectiva de agregar valor aos processos de ensino presencial.

Baseado no modelo de ensino híbrido o presente trabalho de pesquisa teve como objetivo realizar uma revisão bibliográfica integrativa sobre pesquisas que mostram as potencialidades pedagógicas oferecidas pelo Google sala de aula (Classroom) como ambiente virtual de aprendizagem para o ensino superior híbrido.

\section{Metodologia}

Para o desenvolvimento do presente trabalho de pesquisa realizou-se uma revisão bibliográfica integrativa sobre a ferramenta Google sala de aula. A revisão integrativa permite a inclusão de estudos experimentais e não-experimentais para uma compreensão completa do fenômeno analisado (SOUZA, SILVA \& CARVALHO, 2010). Além disso, busca sintetizar resultados de pesquisas sobre determinado assunto de forma sistemática e organizada. Para tanto devem ser consideradas algumas etapas como: identificação do tema para a revisão; seleção de critérios de inclusão e exclusão de estudos; categorização dos estudos; avaliação; interpretação dos resultados e apresentação da revisão com uma análise crítica dos achados (MENDES, SILVEIRA \& GALVÃO, 2008).

Dessa forma, para a construção da revisão integrativa foi necessário partir de uma questão norteadora, a saber: Quais as potencialidades oferecidas pela ferramenta Google sala de aula como ambiente virtual de aprendizagem para o ensino superior híbrido? Assim, foi realizada coleta de dados, especificamente publicações científicas relacionadas com temáticas: Google sala de aula como Ambiente Virtual de Aprendizagem (AVA), Blended Learning no ensino superior, e Tecnologias Digitais da Informação e da Comunicação (TDICS) no contexto educacional. Para a seleção das publicações foram estabelecidos alguns critérios de inclusão, como: artigo completo, periódicos avaliados por pares, publicados entre os anos 2014 a 2018. Esse período foi determinado devido ao lançamento global da Plataforma Google Sala de Aula, a partir de maio de 2014. E exclusão, como o uso do Google sala de aula como Ambiente Virtual de Aprendizagem na educação básica. Os textos analisados estão disponíveis on-line ou em material impresso e redigidos em português, inglês ou espanhol. As bases de dados utilizadas na busca dos artigos foram o Portal de Periódicos da Capes e o Google Acadêmico.

Visando obedecer aos critérios de seleção, buscou-se identificar trabalhos que se aproximavam da temática delimitada a partir da leitura dos resumos e do acesso aos textos completos. Os artigos encontrados foram submetidos a uma análise descritiva com base em características singulares como: periódico (número, volume e ano); autor (es); procedência do (s) autor (es); título do artigo; natureza do artigo (original, revisão, relato de experiência e estudo de caso); temática central; tipo de abordagem (metodologia) e descrição do conteúdo. Para facilitar a compreensão da evolução do conhecimento na área de estudo, os artigos foram agrupados por temas pertinentes ao assunto estudado.

\section{Resultados e Discussão}

O ensino superior presencial encontra-se em processo de plena hibridização, principalmente após a revogação da Portaria n 1.134/2016 e a publicação da Portaria n 1.428, de 28 de dezembro de 2018. Essa 
portaria dispõe sobre a oferta de disciplinas com metodologia a distância em cursos de graduação presencial, por Instituições de Educação Superior- IES credenciadas pelo Ministério da Educação. A mesma define em seu artigo terceiro que, a oferta de disciplinas na modalidade a distância poderá ser ampliada para até 40\% (quarenta por cento) para cursos de graduação presencial, desde que as instituições atendam aos requisitos previstos pela legislação vigente (ASSOCIAÇÃO BRASILEIRA DE MANTENEDORAS DE ENSINO SUPERIOR- ABMES, 2018). Neste contexto, ocorre o processo de virtualização da sala de aula, com a popularização do uso de ambientes virtuais de aprendizagem em cursos presenciais, dentre eles, o Google Sala de Aula, foco deste trabalho.

Diante deste cenário o presente trabalho de pesquisa realizou uma busca por referências bibliográficas que abordassem os temas pertinentes ao assunto sobre hibridização do ensino superior com o uso da ferramenta Google sala de aula. A busca resultou em 23 publicações, como podemos observar no Quadro 1.

QUADRO 1: Relação de publicações encontradas no período de 2014 a 2018.

\begin{tabular}{|c|c|c|c|}
\hline TÍTULO & $\begin{array}{l}\text { TIPO DE } \\
\text { ESTUDO }\end{array}$ & AUTOR (ES) & $\begin{array}{c}\text { ANO DE } \\
\text { PUBLICAÇÃO }\end{array}$ \\
\hline $\begin{array}{l}\text { Educação a distância em instituições de } \\
\text { ensino superior: uma revisão de pesquisas }\end{array}$ & Teórico & $\begin{array}{l}\text { MARTINS, L. B.; } \\
\text { ZERBINI, T. }\end{array}$ & 2014 \\
\hline $\begin{array}{l}\text { Blended learning e as mudanças no ensino } \\
\text { superior: a proposta da sala de aula } \\
\text { invertida }\end{array}$ & Teórico & VALENTE, J. A. & 2014 \\
\hline $\begin{array}{l}\text { O emprego das tecnologias de informação e } \\
\text { comunicação no ensino superior: relato de } \\
\text { experiência sobre a oficina modelo híbrido } \\
\text { de ensino. }\end{array}$ & Experimental & $\begin{array}{l}\text { PEIXOTO, R. T. R. } \\
\text { da C.; GONÇALVES, } \\
\text { P. V. A. J.; AMORIM, } \\
\text { H. C. S.; ARAÚJO, A. } \\
\text { V. A. }\end{array}$ & 2015 \\
\hline $\begin{array}{l}\text { Aprender e ensinar com foco na } \\
\text { educação híbrida }\end{array}$ & Teórico & $\begin{array}{l}\text { BACICH, L.; } \\
\text { MORAN, J. }\end{array}$ & 2015 \\
\hline $\begin{array}{l}\text { Contribuições do Google Sala de Aula para o } \\
\text { ensino híbrido }\end{array}$ & Teórico & $\begin{array}{l}\text { SCHIEHL, E. P.; } \\
\text { GASPARINI, I. }\end{array}$ & 2016 \\
\hline $\begin{array}{l}\text { Ensino híbrido: proposta de formação } \\
\text { de professores para uso integrado das } \\
\text { tecnologias digitais nas ações de ensino e } \\
\text { aprendizagem }\end{array}$ & Experimental & $\mathrm{BACICH}, \mathrm{L}$. & 2016 \\
\hline $\begin{array}{l}\text { Abordagem híbrida no ensino superior: } \\
\text { reflexões teórico-metodológicas }\end{array}$ & Teórico & $\begin{array}{l}\text { CERUTTI, E.; } \\
\text { MELO, L. F. de }\end{array}$ & 2017 \\
\hline $\begin{array}{l}\text { Hibridização do ensino nos cursos de } \\
\text { graduação presenciais das universidades } \\
\text { federais: uma análise da regulamentação }\end{array}$ & Teórico & $\begin{array}{l}\text { SILVA, M. R. C. da; } \\
\text { MACIEL, C.; } \\
\text { ALONSO, K. M. }\end{array}$ & 2017 \\
\hline $\begin{array}{l}\text { As perspectivas de avaliar o estudante no } \\
\text { ensino híbrido }\end{array}$ & Teórico & $\begin{array}{l}\text { SCHIEHL, E.P.; } \\
\text { KEMCZINSKI, A.; } \\
\text { GASPARINI, I. }\end{array}$ & 2017 \\
\hline $\begin{array}{l}\text { Tecnologias da informação e comunicação } \\
\text { como inovação no ensino superior } \\
\text { presencial: uma análise das variáveis } \\
\text { que influenciam na sua adoção }\end{array}$ & Teórico & $\begin{array}{l}\text { CALIARI, K. V. Z.; } \\
\text { ZILBER, M. A.; } \\
\text { PEREZ, G. }\end{array}$ & 2017 \\
\hline $\begin{array}{l}\text { Blended learning: uma proposta para } \\
\text { o ensino híbrido }\end{array}$ & Teórico & CAMILLO, C. M. & 2017 \\
\hline $\begin{array}{l}\text { Blended learning potencializando a aprendi- } \\
\text { zagem da Estatística no ensino superior }\end{array}$ & Experimental & $\begin{array}{l}\text { MOURA, G. M.; } \\
\text { SAMÁ, S. }\end{array}$ & 2017 \\
\hline
\end{tabular}




\begin{tabular}{|l|l|l|c|}
\hline $\begin{array}{l}\text { Educação híbrida e design instrucional: } \\
\text { estudo de caso no ensino superior } \\
\text { tecnológico }\end{array}$ & Experimental & $\begin{array}{l}\text { CASTRO, A. B. B. de; } \\
\text { MILL, D. }\end{array}$ & 2018 \\
\hline $\begin{array}{l}\text { O Google Sala de Aula como interface de } \\
\text { aprendizagem no ensino superior }\end{array}$ & Teórico & SILVA, E. C. S. da & 2018 \\
\hline $\begin{array}{l}\text { Um relato de experiência usando Google } \\
\text { Sala de Aula para apoio à aprendizagem } \\
\text { de química }\end{array}$ & Experimental & $\begin{array}{l}\text { SILVA, G. M. L. da; } \\
\text { MAGALHÃES NETTO, } \\
\text { J.F. de. }\end{array}$ & 2018 \\
\hline $\begin{array}{l}\text { O uso das ferramentas do aplicativo } \\
\text { "Google Sala de Aula" no ensino de História }\end{array}$ & Experimental & $\begin{array}{l}\text { NASCIMENTO, A. } \\
\text { N. do }\end{array}$ & 2018 \\
\hline $\begin{array}{l}\text { Uso das tecnologias da informação e comu- } \\
\text { nicação na educação de jovens e adultos }\end{array}$ & Experimental & $\begin{array}{l}\text { PEREIRA, L. K.; } \\
\text { MÜNCHEN, G. }\end{array}$ & 2018 \\
\hline $\begin{array}{l}\text { Blended learning: o ensino híbrido e a avalia- } \\
\text { ção da aprendizagem no ensino superior }\end{array}$ & Teórico & $\begin{array}{l}\text { SPINARDI, J. D.; } \\
\text { BOTH, I. J. }\end{array}$ & 2018 \\
\hline $\begin{array}{l}\text { A utilização de tecnologias de informação } \\
\text { e comunicação (TICs) como ferramenta } \\
\text { para minimizar os altos índices de retenção } \\
\text { e evasão na disciplina de Função de uma } \\
\text { variável (Cálculo I) no BCT/UFVJM. }\end{array}$ & Experimental & $\begin{array}{l}\text { ALVES, A. C.; } \\
\text { GUIMARÃES, L. M.; } \\
\text { PIMENTA, T. S. }\end{array}$ & 2018 \\
\hline $\begin{array}{l}\text { O uso das tecnologias para uma educação } \\
\text { autônoma no curso de Direito }\end{array}$ & Experimental & $\begin{array}{l}\text { ARAKAKI, F. F. S.; } \\
\text { MENDES, A. A.; } \\
\text { OLIVEIRA, L. M. M. } \\
\text { M. DE }\end{array}$ & 2018 \\
\hline $\begin{array}{l}\text { Ensino híbrido (blended learning) potencial e } \\
\text { desafios no ensino superior }\end{array}$ & Teórico & $\begin{array}{l}\text { LEANDRO, S. M.; } \\
\text { CORRÊA, E. M. }\end{array}$ & 2018 \\
\hline $\begin{array}{l}\text { Percepção dos alunos da geração Y sobre o } \\
\text { uso de novas tecnologias em ambientes de } \\
\text { aprendizagem }\end{array}$ & Experimental & $\begin{array}{l}\text { SOUZA, W. C. DE; } \\
\text { MATTOS, M. C. DE }\end{array}$ & 2018 \\
\hline $\begin{array}{l}\text { Regulamentação da oferta de disciplinas } \\
\text { EaD em 20\% da carga horária total dos } \\
\text { cursos presenciais e a virtualização da } \\
\text { educação superior }\end{array}$ & Teórico & $\begin{array}{l}\text { TEIXEIRA, T. F.; } \\
\text { FERREIRA, E. D.; } \\
\text { MICHELS, E. }\end{array}$ & 2018 \\
\hline
\end{tabular}

Os trabalhos apresentaram-se em dois grupos distintos: artigos científicos publicados em periódicos nacionais, com $60,87 \%$ do total e de trabalhos completos apresentados em anais de congresso nacionais e internacionais, com 39,13\%, dentre eles o "Congresso Internacional de Educação e Tecnologias/ Encontro de Pesquisadores em Educação a Distância (CIET- EnPED)", "Congresso Brasileiro de Informática na Educação", "Simpósio Tecnologias e Educação a Distância no Ensino Superior", todos esses eventos ocorreram no ano de 2018. Sendo distribuídos da seguinte forma: 2 publicações em 2014, 2 publicações em 2015, 2 publicações em 2016, 6 publicações em 2017 e 11 publicações em 2018 (Quadro 1).

Isso é reflexo de uma plataforma ainda recente, quando comparada a outros ambientes virtuais de aprendizagem já consolidados como o Moodle. Observa-se também que dentre os trabalhos analisados, $56,52 \%$ abordavam estudos teóricos, e 43,48\% estudos experimentais, com o uso das TDICs por estudantes ou profissionais da educação. Apenas no ano de 2018 foram encontradas publicações que abordavam especificamente a plataforma Google sala de aula, cujo os autores foram: Carneiro, Lopes, Campos Neto, 2018; Silva, Magalhães Netto, 2018; Nascimento, 2018; Arakaki et al., 2018), e desde então houve um aumento de estudos referentes a temática. Dentre estes estudos observou-se ainda uma diversidade de aplicação da plataforma que englobou áreas como: Direito (ARAKAKI et al., 2018), História (NASCIMENTO, 2018) e Química (SILVA, MAGALHÃES NETTO, 2018) obtendo resultados positivos quanto ao uso, seja em um assunto específico, uma disciplina ou curso. 
Alguns autores se destacaram quanto ao número de artigos publicados nesse período, são eles: Bacich com uma publicação em 2015 e outra em 2016. Na primeira realizou um estudo teórico sobre "Aprender e ensinar com foco na educação híbrida" e na segunda com um estudo experimental sobre uma "Proposta de formação de professores para uso integrado das tecnologias digitais nas ações de ensino e aprendizagem". E o autor Schield e colaboradores também com duas publicações sendo uma em 2016 e outra em 2017, ambas do tipo teórica, “Contribuições do Google Sala de Aula para o ensino híbrido”, e a outra sobre "As perspectivas de avaliar o estudante no ensino híbrido".

Quanto aos trabalhos que adotaram uma abordagem teórica pode-se destacar algumas publicações tanto de artigo original quanto de artigos completos publicados em eventos. Um deles é o trabalho desenvolvido por Martins e Zernini (2014) sobre a crescente inserção do Ensino a Distância em instituições de ensino superior tanto em universidades brasileiras, quanto em outras instituições em nível mundial, como Índia, Espanha, Japão, Alemanha, Portugal, Canadá e Venezuela. Já aqueles que realizaram estudos experimentais destacam-se as publicações do tipo relato de experiência, como: Peixoto et al., (2015) e Bacich (2016), ambos relacionados com a formação de professores e de estudo de caso, como: Moura \& Samá (2017) e Castro \& Mill (2018), que resultaram em estudo sobre a percepção dos alunos sobre o uso do ensino híbrido em determinada disciplina.

A síntese e a discussão dos principais resultados de pesquisas levantados foram divididas em eixos temáticos, para uma melhor compreensão e análise dos dados, a saber: 1) Ensino a distância; 2) Ensino híbrido no ensino superior; e 3) Google Sala de Aula como Plataforma Virtual de Aprendizagem no ensino superior híbrido.

Na categoria temática "Ensino a distância" foram encontrados apenas trabalhos do tipo revisão bibliográfica, e estudo de caso (Tabela 1). Já na categoria temática "Ensino híbrido", foram encontrados o maior número de publicações, tanto do tipo revisão bibliográfica $(57,14 \%)$, como relato de experiência $(7,14 \%)$ e estudo de caso (21,43\%), como mostra a Tabela 1. Quanto ao eixo temático "Google Sala de aula" foram encontradas publicações apenas em periódicos e eventos nacionais e internacionais, do tipo revisão bibliográfica (11,11\%), relato de experiência (22,22\%) e do tipo estudo de caso, também com $11,11 \%$, no recorte temporal fixado entre 2014 a 2018.

Tabela 1: Artigos divididos por categorias temáticas.

\begin{tabular}{|c|c|c|c|}
\hline \multirow[t]{2}{*}{ Categorias temáticas } & \multicolumn{2}{|c|}{ Artigos originais } & \multirow[b]{2}{*}{ Estudo de caso } \\
\hline & Revisão bibliográfica & Relato de experiência & \\
\hline Ensino a Distância & $2(14,28 \%)$ & 0 & 0 \\
\hline Ensino Híbrido & $8(57,14 \%)$ & $1(7,14 \%)$ & $3(21,43 \%)$ \\
\hline Google Sala de Aula & 0 & 0 & 0 \\
\hline Total & 10 & 1 & 3 \\
\hline \multicolumn{4}{|c|}{ Artigos completos- Eventos } \\
\hline & Revisão bibliográfica & Relato de experiência & Estudo de caso \\
\hline Ensino a Distância & $1(11,11 \%)$ & 0 & $2(22,22 \%)$ \\
\hline Ensino Híbrido & $1(11,11 \%)$ & $1(11,11 \%)$ & 0 \\
\hline Google Sala de Aula & $1(11,11 \%)$ & $2(22,22 \%)$ & $1(11,11 \%)$ \\
\hline Total & 3 & 3 & 3 \\
\hline
\end{tabular}




\subsection{Ensino Híbrido}

O ensino híbrido é um sistema de ensino e aprendizagem onde existem conteúdos ofertados a distância, mediados por tecnologia e conteúdos necessariamente ofertados presencialmente (FAVA, 2014). Ao comparar o ensino tradicional com o ensino híbrido Schiehl e Gasparini (2016) destacam que o primeiro compartilha o mesmo ambiente físico e proporciona o aprendizado do estudante em sala de aula, na presença do professor e colegas e o segundo compartilha o mesmo ambiente virtual.

Assim, tendo como foco o ensino híbrido, Schiehl e Gasparini (2016) destacaram dois tipos, um progressivo chamado de sustentado e outro mais radical, definido como disruptivo (Figura 1). O primeiro permite uma inserção gradativa nos ambientes educacionais, sem gerar grandes rupturas no modelo tradicional, mas com a visão de melhorias no ensino e no aprendizado. Dentre eles podemos citar três: rotação por estações, sala de aula invertida e laboratório rotacional. Já o segundo organiza-se de forma que a maior parte do tempo de aula seja on-line, e incluem os modelos: rotação individual, Flex, à La carte e virtual enriquecido (CHRISTENSEN, HORN \& STAKE, 2013; BACICH, TANZI NETO \& TREVISANI, 2015).

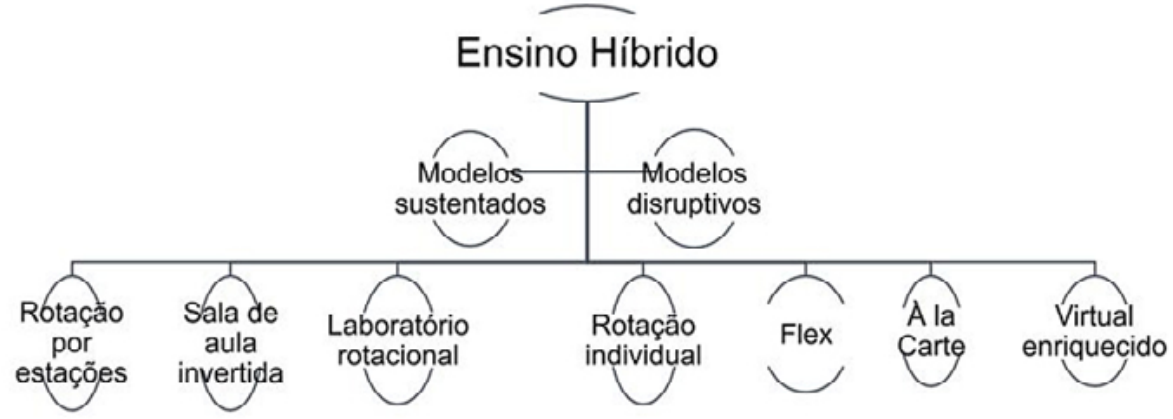

Figura 1: Tipos de modelos sustentados e disruptivos presentes no ensino híbrido.

No presente trabalho de pesquisa o modelo mais encontrado nas publicações foi sala de aula invertida. Esta modalidade foi vista em estudos realizados pelo pesquisador Valente (2014), que fez uma análise sobre as mudanças no ensino superior com o uso do ensino híbrido, especificamente a sala de aula invertida e Camillo (2017) que analisou as diferentes modalidades do ensino híbrido no ensino superior e, em especial a sala de aula invertida e as contribuições do método para o aprendizado do aluno.

Spinardi e Both (2018) enfatizaram a relação entre a aula tradicional e o tempo de aula e atividades extraclasse e o uso dessa modalidade de ensino invertido, onde o aluno estuda o conteúdo em um Ambiente Virtual de Aprendizagem (AVA) antes de ir para sua aula presencial. Isso permite que os professores usem o tempo de aula para realização de projetos, debates e discussões sobre assuntos pesquisados em sala de aula. E tudo que antes era feito na sala de aula (explicação do conteúdo) é agora feito em casa e, o que era feito em casa (aplicação, atividades sobre o conteúdo), é agora feito em sala de aula (BACICH, 2016). Destaca-se que a sala de aula invertida é a prática que vem sendo pensada para ampliar as novas práticas pedagógicas. Oportunizando ao aluno de Ensino Superior uma aula presencial pelo professor e a aplicação de conteúdo e de atividades online para que seja mantida a introdução e/ou a continuidade da aula.

Neste sentido, faz-se necessário que as TDICs estejam bem integradas no processo de aprendizagem, para que apoiem as práticas desenvolvidas em sala de aula. A otimização do trabalho com as TDICs requer, portanto, mudanças fundamentais tanto por parte dos professores, alunos e gestores de escolas e/ ou universidades. 


\subsection{Google Sala de Aula}

A tecnologia aliada ao uso de Ambientes Virtuais de Aprendizagem, modificou a maneira de ensinar, fazendo com que os limites de tempo e espaço se expandissem (YUEH \& HSU, 2008). Ally (2004) afirma que, o tempo de atualização no espaço virtual é bem mais ágil do que no físico, e que o professor consegue disponibilizar conteúdos atualizados em um curto espaço de tempo.

A Google Suite for Education (Gsuite) oferece um conjunto de ferramentas de comunicação e produtividade destinadas a promover a colaboração e a criatividade, que incluem: Gmail, Google Docs, Google Drive e Google Sala de Aula. Dentre este conjunto de ferramenta tem-se destacado o Google Sala de Aula (Figura 2), que consiste em uma sala virtual, onde o professor organiza, acompanha, atribui comentários, insere notas para as produções realizadas pelos alunos, previamente cadastrados (WITT, 2015). Atualmente existe uma parceria entre a empresa Google e as universidades públicas brasileiras para oferta desse tipo de serviço gratuitamente. Assim, todos os envolvidos no processo educacional desenvolvem a confiança com a tecnologia, possibilitando uma aprendizagem mais significativa no contexto de sala de aula.

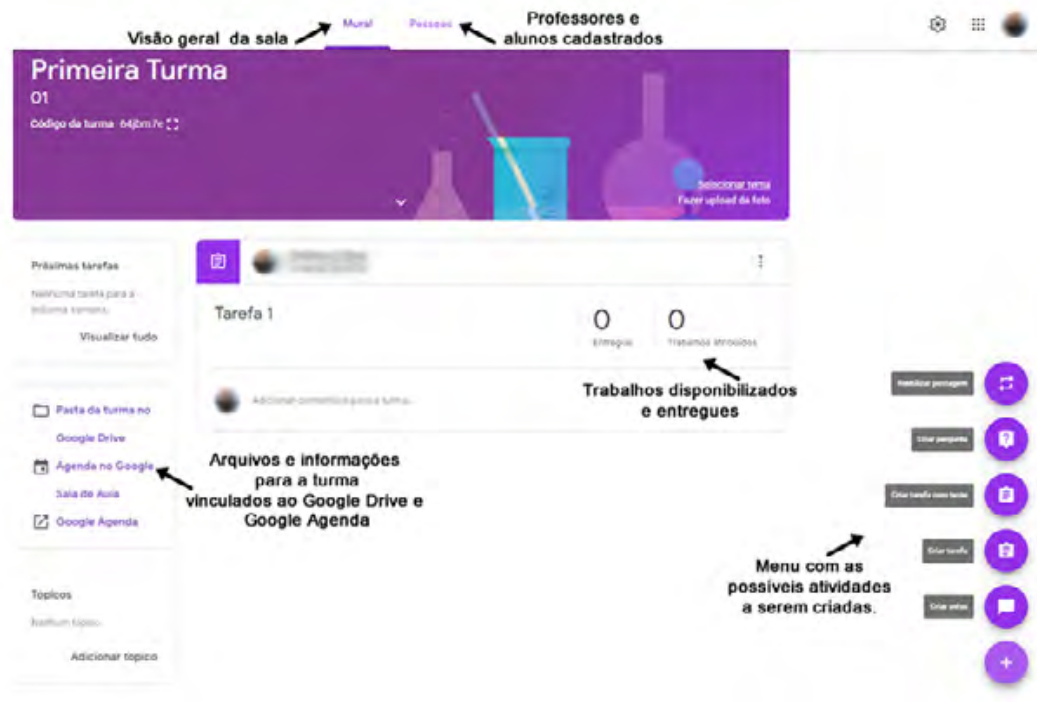

Figura 2: Interface gráfica de uma sala de aula virtual, criada na plataforma Google Sala de Aula.

Em estudos realizados por Schiehl e Gasparini (2016) foi visto que além dos alunos, o professor responsável pela turma pode cadastrar outras pessoas como: o coordenador pedagógico, professores de outras disciplinas, ou até mesmo os pais dos alunos. Sousa Júnior et al. (2017) descreveram algumas vantagens do uso dessa ferramenta, são elas: fácil manuseio, promove a aprendizagem on-line, auxilia os professores na postagem e recebimento de atividades, dentro e fora da sala de aula, apresenta-se em idioma português, além de ser acessado através de um computador ou smartphone, está interligada ao Google Drive. Possibilita ainda disponibilizar materiais sobre os conteúdos preparados em aula, inserir documentos, formulários, vídeos, apresentações, entre outros. O estudante poderá ver, rever e desenvolver suas atividades a qualquer momento uma vez que esses documentos ficam à sua disposição. Além disso, o mesmo poderá acompanhar seu desempenho bem como o prazo de cada atividade, pois as informações ficam registradas no Google Sala de Aula. Em caso de dúvida em alguma atividade extraclasse, os estudantes poderão entrar em contato com o professor tanto de forma síncrona como assíncrona.

Portanto, o Google Sala de Aula é uma plataforma que possibilita a interação, organização e a orientação personalizada ao ritmo de estudo do estudante. Pesquisadores relatam que os estudantes se sentem mais motivados com o uso do Google Sala de Aula, e que favorece o aprendizado significativo (DICICCO, 
2016). No entanto, são necessários mais estudos, principalmente na adequação de metodologias com o uso da plataforma.

\section{Considerações Finais}

Diante do exposto, pode-se observar que a ferramenta Google Sala de Aula possibilita mesclar a sala de aula tradicional com recursos digitais, pelos quais o aluno pode estudar em uma sala de aula virtual, em seu próprio ritmo. Além disso, oferece um rápido feedback, processo considerado o motor de reorientação, ou seja, todos os componentes usados para verificar a aprendizagem precisam reagir aos resultados obtidos pelos alunos em uma determinada atividade.

Além disso, destaca-se a convergência entre os três eixos temáticos analisados (Ensino a distância, Ensino híbrido e Google Sala de Aula como Plataforma Virtual de Aprendizagem). Pois os mesmos envolvem uma grande tendência pedagógica a partir do desenvolvimento das TDICs, uma vez que proporcionam a personalização do ensino.

O problema apresentado no início deste artigo - "Quais as potencialidades da plataforma Google sala de aula como ferramenta de apoio ao ensino híbrido superior? Pode ser respondido por meio da compreensão de que essa ferramenta permite aos alunos maior flexibilidade para estudar em momentos on-line, através de um computador ou smartphone, bem como em momentos presenciais com a mediação de um professor e a interação com os colegas.

Diante das características apresentadas pela ferramenta e pelas suas potencialidades, acredita-se que se trata de uma alternativa relevante para popularização do ensino híbrido na educação superior brasileira. Em vista disso sugere-se novos estudos a respeito do tema de forma que o mesmo seja investigado profundamente por meio de pesquisas de campo em instituições de ensino.

\section{Referências Bibliográficas}

ALLY, M. Foundations of educational theory for on-line learning. In: ANDERSON, T.; ELIOUMI, F. Theory and practice of on-line learning. Athabasca: Athabasca University, 2004. Disponível em: http://cde. athabascau.ca/online book/pdf/TPOL book.pdf. Acesso em: 24 set. 2018.

ALVES, A. C.; GUIMARÃES, L. M.; PIMENTA, T. S. A utilização de tecnologias de informação e comunicação (TIC) como ferramenta para minimizar os altos índices de retenção e evasão na disciplina de função de uma variável (Cálculo I) NO BCT/UFVJM. In: SIMPÓSIO TECNOLOGIAS E EDUCAÇÃO A DISTÂNCIA NO ENSINO SUPERIOR. Anais... Belo Horizonte: STEDES, 2018. Disponível em: http://revista.uemg.br/ index.php/Simposioteceedadistnoenssuperior/article/view/3014. Acesso em: 09 out. 2018.

ARAKAKI, F. F. S.; MENDES, A. A.; OLIVEIRA, L. M. M. M. de. O uso das tecnologias para uma educação autônoma no curso de Direito. In: SIMPÓSIO TECNOLOGIAS E EDUCAÇÃO A DISTÂNCIA NO ENSINO SUPERIOR. Anais... Belo Horizonte: STEDES, 2018. Disponível em: http://revista.uemg.br/index.php/ Simposioteceedadistnoenssuperior/article/view/3001/1690. Acesso em: 03 out. 2018.

BACICH, L. Ensino híbrido: proposta de formação de professores para uso integrado das tecnologias digitais nas ações de ensino e aprendizagem. In: VII CONGRESSO BRASILEIRO DE INFORMÁTICA NA EDUCAÇÃO: WORKSHOP DE INFORMÁTICA NA ESCOLA, 5, 2016. Anais... Fortaleza: CBIE/WIE, 2016. p. 679-687. Disponível em: http://www.br-ie.org/pub/index.php/wie/article/view/6875. Acesso em: 20 out. 2018. 
; MORAN, J. Aprender e ensinar com foco na educação híbrida. Revista Pátio, n. 25, p. 45-47, 2015. Disponível em: http://www.grupoa.com.br/revistapatio/artigo/11551/aprender-e-ensinar-com-focona-educacao-hibrida.aspx. Acesso em: 09 out. 2018.

; TANZI NETO, A.; TREVISANI, F. M. Ensino híbrido: personalização e tecnologia na educação. Porto Alegre: Penso, 2015.

BRASIL. MEC. Portaria n¹.428, de 28 de dezembro de 2018. Dispõe sobre a oferta, por instituições de educação superior - IES, de disciplinas na modalidade a distância em cursos de graduação presencial. Diário Oficial da União: seção 1, Brasília, n. 250, p. 59, 31 dez. 2018. Disponível em: http://www.in. gov.br/materia/-/asset_publisher/Kujrw0TZC2Mb/content/id/57496468/do1-2018-12-31-portaria-n-1428-de-28-de-dezembro-de-2018-57496251. Acesso em: 20 fev. 2019.

CAMILLO, C. M. Blended learning: uma proposta para o ensino híbrido. Revista EaD \& Tecnologias Digitais na Educação, v. 5, n. 7, p. 64-74, 2017. Disponível em: https://doi.org/10.30612/eadtde.v5i7.6660. Acesso em: 20 out. 2018.

CALIARI, K. V. Z.; ZILBER, M. A., PEREZ, G. Tecnologias da informação e comunicação como inovação no ensino superior presencial: uma análise das variáveis que influenciam na sua adoção. REGE - Revista de Gestão, v. 24, p. 247-255, 2017. Disponível em: http://dx.doi.org/10.1016/j.rege.2017.05.003. Acesso em: 25 nov. 2018.

CARNEIRO, J. R. S.; LOPES, A. S. B.; CAMPOS NETO, E. B. A utilização do Google Sala de Aula na Educação Básica: uma plataforma pedagógica de apoio à Educação contextualizada. In: VII CONGRESSO BRASILEIRO DE INFORMÁTICA NA EDUCAÇÃO: WORKSHOP DE INFORMÁTICA NA ESCOLA, 7, 2018. Anais... Fortaleza: CBIE/WIE, 2018. p. 401-410. Disponível em: http://www.br-ie.org/pub/index.php/wie/article/ view/7909/5608. Acesso em: 20 nov. 2018.

CASTRO, A. B. B. de; MILL, D. Educação híbrida e design instrucional: estudo de caso no Ensino Superior Tecnológico. Revista Diálogo Educacional, v. 18, n. 58, p. 760-778, 2018. Disponível em: http://dx.doi. org/10.7213/1981-416X.18.058.DS08. Acesso em 23 out. 2018.

CERUTTI, E.; MELO, L. F. de. Abordagem híbrida no ensino superior: reflexões teórico-metodológicas. RPGE - Revista on line de Política e Gestão Educacional, v. 21, n. esp. 1, p. 605-620, 2017. Disponível em: http://dx.doi.org/10.22633/rpge.v21.n.esp1.out.2017.9826. Acesso em 20 out. 2018.

CHRISTENSEN, C.; HORN, M. B.; STAKER, H. Ensino híbrido: uma inovação disruptiva? Uma introdução à teoria dos híbridos. 2013. Disponível em: https://s3.amazonaws.com/porvir/wp-content/uploads/2014/08/PT Is-K-12-blendedlearning-disruptive-Final.pdf. Acesso em: 19 out. 2018.

DICICCO, K. M. The effects of Google Classroom on teaching social studies for students with learning disabilities. 2016. Dissertação (Master of Arts in Special Education), Rowan University. Nova Jersey, 2016. Disponível em: https://rdw.rowan.edu/cgi/viewcontent.cgi?article=2583\&context=etd. Acesso em: 26 out. 2018.

FARIA, E. T. O professor e as novas tecnologias. In: ENRICONE, D. (Org.). Ser professor. $4^{\text {a }}$ ed. Porto Alegre: EDIPUCRS, 2004. p. 57-72. Disponível em: http://aprendentes.pbworks.com/f/prof_e_a_tecnol_5[1]. pdf. Acesso em: 22 out. 2018.

FAVA, R. Educação 3.0: aplicando o PDCA nas instituições de ensino. São Paulo: Saraiva, 2014.

LEANDRO, S. M.; CORRÊA, E. M. Ensino híbrido (blended learning) potencial e desafios no ensino superior. In: CONGRESSO INTERNACIONAL DE EDUCAÇÃO E TECNOLOGIAS: ENCONTRO DE PESQUISADORES EM EDUCAÇÃO A DISTÂNCIA, 2018. Anais... São Carlos: CIET-EnPED, 2018. Disponível em: http://cietenped.ufscar.br/submissao/index.php/2018/article/view/24. Acesso em: 28 nov. 2018. 
MACIEL, C. Educação a distância: ambientes virtuais de aprendizagem. Cuiabá: EdUFMT, 2013.

MARTINS, L. B.; ZERBINI, T. Educação a distância em instituições de ensino superior: uma revisão de pesquisas. Revista Psicologia: Organizações e Trabalho, v. 14, n. 3, p. 271-282, 2014. Disponível em: http://submission-pepsic.scielo.br/index.php/rpot/index. Acesso em 15 out. 2018.

MENDES, K. D. S.; SILVEIRA, R. C. de C. P.; GALVÃO, C. M. Revisão integrativa: método de pesquisa para a incorporação de evidências na saúde e na enfermagem. Texto Contexto Enfermagem, v. 17, n. 4, p. 758-764, 2008. Disponível em: http://dx.doi.org/10.1590/S0104-07072008000400018. Acesso em: 02 out. 2018.

MENDES, S. M. C.; LEME, M. E. G. A mediação pedagógica: formação docente para a educação inclusiva frente às novas tecnologias. Brazilian Journal of Technology, Communication, and Cogntive Science, v. 2, n. 2, p. 1-12, 2014. Disponível em: http://www.anais.tecccog.net/index.php/anais/article/ view/11. Acesso em: 14 out. 2018.

MORAN, J. Educação híbrida: um conceito-chave para a educação, hoje. In: BACICH, L.; TANZI NETO, A.; TREVISANI, F. M. (Orgs.). Ensino híbrido: personalização e tecnologia na educação. Porto Alegre: Penso, 2015.

MOURA, G. M.; SAMÁ, S. Blended learning potencializando a aprendizagem da estatística no ensino superior. Informática na Educação: Teoria \& Prática, v. 20, n. 1, p. 60-70, 2017. Disponível em: https:// seer.ufrgs.br/InfEducTeoriaPratica/article/view/70616/41084. Acesso em 12 out. 2018.

NASCIMENTO, A. N. do. O uso das ferramentas do aplicativo Google Sala de Aula no ensino de História. In: SEMINÁRIO DEBATES DO TEMPO PRESENTE: DESAFIOS PARA AS HUMANIDADES EM TEMPOS DE CRISE, 2, 2018. Anais... Aracaju: SDTP, 2018. p. 309- 320. Disponível em: https://encuentros.virtualeduca.red/storage/ponencias/bahia2018/hwXpvp9PKp0aNvStoQd6GfA53g5HPqT3y0vpB2nd.pdf. Acesso em: 25 out. 2018 .

PEIXOTO, R. T. R. da C.; GONÇALVES, P. V. A. J.; ALVIM, H. H.; AMORIM, H. C. S.; ARAÚJO, A. V. A. O emprego das tecnologias de informação e comunicação no ensino superior: relato de experiência sobre a oficina Modelo Híbrido de Ensino. Revista Docência do Ensino Superior, v. 5, n. 1, p. 183-204, 2015. Disponível em: https://seer.ufmg.br/index.php/rdes/article/view/917/710. Acesso em: 14 out. 2018.

PEREIRA, K. L.; MÜNCHEN, G. Uso das tecnologias da informação e comunicação na educação de jovens e adultos. In: CONGRESSO INTERNACIONAL DE EDUCAÇÃO E TECNOLOGIAS: ENCONTRO DE PESQUISADORES EM EDUCAÇÃO A DISTÂNCIA, 2018. Anais... São Carlos: CIET-EnPED, 2018. Disponível em: http://cietenped.ufscar.br/submissao/index.php/2018/article/view/307. Acesso em: 03 nov. 2018.

REZENDE, Wanderley Moura; DIAS, Ana Isabel de Azevedo Spinola. Educação a distância e ensino presencial: incompatibilidade ou convergência? EaD em foco, v. 1, n. 1, abr. 2010.Disponível em: https://doi. org/10.18264/eadf.v1i1.10. Acesso em: 22 maio 2019.

SANCHO, M.; HERNÁNDEZ, F. Tecnologias para transformar a educação. Porto Alegre: Artmed, 2006.

SCHIEHL, E. P.; GASPARINI, I. Contribuições do Google Sala de Aula para o ensino híbrido. Revista Renote: Novas Tecnologias na Educação, v. 14, n. 2, 2016. Disponível em: https://doi.org/10.22456/16791916.70684. Acesso em: 02 set. 2018.

; KEMCZINSKI, A.; GASPARINI, I. As perspectivas de avaliar o estudante no ensino híbrido. Revista Renote: Novas Tecnologias na Educação, v. 15, n. 2, 2017. Disponível em: https://doi.org/10.22456/16791916.79280. Acesso em: 07 nov. 2018. 
SILVA, E. C. S. da. O Google Sala de Aula como interface de aprendizagem no ensino superior. In: $9^{\circ}$ SIMPÓSIO INTERNACIONAL DE EDUCAÇÃO E COMUNICAÇÃO ( $9^{\circ}$ SIMEDUC), 2018. Anais... Aracaju: $9^{\circ}$ SIMEDUC, 2018. Disponível em: https://eventos.set.edu.br/index.php/simeduc/article/viewFile/9572/4164. Acesso em: 07 nov. 2018.

SILVA, G. M. L. da; MAGALHÃES NETTO, J. F. de. Um relato de experiência usando Google Sala de Aula para apoio à aprendizagem de Química. In: CONGRESSO BRASILEIRO DE INFORMÁTICA NA EDUCAÇÃO / WORKSHOP DE INFORMÁTICA NA ESCOLA, 7, 2018. Anais... Fortaleza: CBIE/WIE, 2018. Disponível em: http://doi.org/10.5753/cbie.wie.2018.119. Acesso em: 16 nov. 2018. p. 119-128.

SILVA, M. R. C. da; MACIEL, C.; ALONSO, K. M. Hibridização do ensino nos cursos de graduação presenciais das universidades federais: uma análise da regulamentação. RBPAE - Revista Brasileira de Política e Administração da Educação, v. 33, n. 1, p. 95-117, 2017. Disponível em: https://doi.org/10.21573/ vol33n12017.74042. Acesso em: 16 nov. 2018.

SILVEIRA, C. R. Metodologia da pesquisa. 2. ed. rev. e atual. Florianópolis: Publicações do IFSC, 2011. Disponível em: http://educapes.capes.gov.br/handle/capes/206318. Acesso em: 05 nov. 2018.

SOUSA JÚNIOR, A.; OLIVEIRA, C.; BRAGA, E.; LIMA, V. A. de. Google Suite for education: trazendo o Google Classroom como uma perspectiva para as salas de aula usando os dispositivos móveis. In: CONGRESSO SOBRE TECNOLOGIAS NA EDUCAÇÃO, 2, 2017. Anais... João Pessoa: CTE, 2017. Disponível em: http://ceur-ws.org/Vol-1877/CtrlE2017 AC 11 19.pdf. Acesso em: 3 out. 2018.

SOUZA, M. T. de; SILVA, M. D. da; CARVALHO, R. de. Revisão integrativa: o que é e como fazer? Einstein, v. 8, n. 1, p. 102-106, 2010. Disponível em: http://www.scielo.br/pdf/eins/v8n1/pt_1679-4508eins-8-1-0102.pdf. Acesso em: 4 set. 2018.

SOUZA, W. C. de; MATTOS, M. C. de. Percepção dos alunos da geração Y sobre o uso de novas tecnologias em ambientes de aprendizagem. Revista FSA, v. 15, n. 6, p. 132-150, 2018. Disponível em: http://dx. doi.org/10.12819/2018.15.6.7. Acesso em: 16 out. 2018.

SPINARDI, J. D.; BOTH, I. J. Blended learning: o ensino híbrido e a avaliação da aprendizagem no ensino superior. Boletim Técnico do Senac, v. 44, n. 1, 2018. Disponível em: http://www.bts.senac.br/index. php/bts/article/view/648. Acesso em: 17 out. 2018.

TEIXEIRA, T. F.; FERREIRA, E. D.; MICHELS, E. Regulamentação da oferta de disciplinas EaD em 20\% da carga horária total dos cursos presenciais e a virtualização da educação superior. In: COLÓQUIO INTERNACIONAL DE GESTÃO UNIVERSITÁRIA, 18, 2018. Anais... Florianópolis: CIGU, 2018. Disponível em: https://repositorio.ufsc.br/bitstream/handle/123456789/190472/101 00121.pdf?sequence $=1 \& \mathrm{i}-$ sAllowed=y. Acesso em: 28 out. 2018.

TORI, R. Educação sem distância: as tecnologias interativas na redução de distâncias em ensino e aprendizagem. São Paulo: Editora Senac São Paulo, 2010.

VALENTE, J. A. Blended learning e as mudanças no ensino superior: a proposta da sala de aula invertida. Educar em Revista, n. 4, p. 79-97, 2014. Disponível em: http://dx.doi.org/10.1590/0104-4060.38645. Acesso em: 27 out. 2018.

; ALMEIDA, M. E. B. de; GERALDINI, A. F. S. Metodologias ativas: das concepções às práticas em distintos níveis de ensino. Revista Diálogos Educacionais, v. 17, n. 52, p. 455-478, 2017. Disponível em: https://periodicos.pucpr.br/index.php/dialogoeducacional/article/view/9900/12386. Acesso em: 30 out. 2018.

WITT, D. Accelerate learning with Google apps for education. 2015. Disponível em: https://danwittwcdsbca.wordpress.com/2015/08/16/accelerate-learning-with-google-apps-for-education/. Acesso em: 8 ago. 2018. 
YUEH, H. P.; HSU, S. Designing a learning management systems to support instruction. Communications of the ACM, v. 5, n. 4, p. 59-63, 2008. Disponível em: http://cacm.acm.org/magazines/2008/4/5440designing-a-learning-management-system-to-support-instruction/abstract. Acesso em: 8 nov. 2018. 